\title{
THE EFFECT OF TOBACCO SMOKE AND OF METHYL IODIDE VAPOR ON THE GROWTH OF CERTAIN MICROORGANISMS*
}

\author{
C. A. Lubwig
}

During the winter of $1916-$ 'I 7 the writer of this paper was engaged in a study of the effect of illuminating gas and its constituents on certain bacteria and fungi (3) and as an accompaniment to this work carried out some similar experiments with tobacco smoke and methyl iodide vapor. Since there is no immediate opportunity to carry these experiments further it has seemed desirable to report briefly on them, although the results attained are necessarily quite preliminary in character. The work was done under the direction of Prof. F. C. Newcombe, for whose help the writer wishes here to extend thanks.

\section{Tobacco Smoke}

Not much experimental work has been reported showing the effect of smoke on bacteria or fungi, although Tassinari (5) showed as long ago as 1888 that tobacco smoke has a retarding effect on a number of pathogenic and non-pathogenic bacteria when they are exposed to the smoke before being put into the sterile nutrient medium. More recently Molisch (4) has shown that tobacco smoke will stop the movements of Chromatium vinosum (Ehrenb.) Winogradsky, Beggiatoa sp., and Spirillum sp.; and that it will retard the growth of Phycomyces nitens.

It is quite impossible, of course, to get any accurate idea as to the composition of any sample of smoke without making an analysis of the sample. A number of papers have been written, however, having an especial bearing on a qualitative determination of the compounds present. No attempt will be made here to summarize this work further than to enumerate some of the compounds found and thus to call attention to the complexity of the mixture called smoke. Vohl and Eulenberg (7) reported a series of hydrocarbons of the benzene series or one analogous to it, and in addition formic, propionic, butyric, Michigan.

* Publication No. I69 from the Botanical Department of the University of 
valerianic, and carbonic acids, creosote, ammonium chloride, ammonia, pyridine, picoline, lutidine, collidine, parvoline, coridine, and rubidine. Kissling (2) reported that the strongly poisonous materials (to man) are carbon monoxide, hydrogen sulphide, hydrocyanic acid, picoline bases and nicotine. To this list of compounds in tobacco smoke Thoms (6) added a phenol boiling at $190-200^{\circ}$, furfural (in small amounts), and a substance boiling at $200-260^{\circ}$ containing sulphur and nitrogen and no terpenes. Crocker and Knight ( $I$, p. 346) have called attention to the presence of ethylene and correlated its presence with the effect of smoke on some phanerogams.

For exact data as to the cultures used and the methods of conducting the experiments reported below the reader is referred to the writer's former paper (3) in which the influence of illuminating gas and its constituents is discussed. For the purpose of filling the culture chamber with smoke the tubulature of the bell jar was fitted with a two-hole rubber stopper carrying two glass tubes such that one extended very little below the stopper while the other extended well toward the bottom of the chamber. The short tube was then connected to an aspirator and the other to a cob pipe. The pipe was filled with tobacco, "Prince Albert" brand, the aspirator started and the tobacco lighted. When the chamber became filled with a white, opaque smoke cloud, the aspirator was stopped and the tubes plugged. The air in the chamber soon became clear, but the upper surface of everything within, and to some extent the vertical surfaces also, became stained brown. The material producing the brown stain did not extend into the test tubes, and consequently not to the agar, because it was clearly limited to the surface of the cotton plugs. No reactions, therefore, can be laid to these products except as they may have been somewhat volatile and therefore capable of diffusing into the tubes. In some of the tests the smoke was passed through one or two wash bottles containing water. In these cases small amounts of a brown oily substance condensed and floated on the surface of the water, and it took longer to produce the opaque cloud in the chamber.

The development of the bacteria in the smoke was rather variable, perhaps owing to an unavoidable lack of uniformity of the conditions in the different trials. There was a strong tendency for the colony development to begin at the bottom of the slant and progress upward after a preliminary period of no growth. No reason can be given for the very pronounced nature of this tendency in smoke. It was ob- 
served, however, that a general but less pronounced tendency for this sort of behavior existed for the cultures in the other gases; and this would seem to indicate that the greater thickness and perhaps moisture content of the substratum at the bottom of the slant together with the heavier inoculation at the beginning of the streak may have had something to do with the results. Apparently the complete prevention of growth at the outset would preclude any assumption that the gases did not diffuse to the bottom of the tubes.

The reports for the following eight organisms are based on two trials in unwashed and one in washed smoke.

Bacillus subtilis.-In the first test there was no visible development in unwashed smoke until the sixth day; in the second test it became visible on the second day. The retardation continued throughout the duration of the 7-day exposure, however, with the washed smoke showing the smaller inhibitive effect. The length of duration of the retarding effect is a point of some significance, as under some circumstances a bacterial culture will show an initial retardation, but will reach a stage of development quite indistinguishable from that of the check within 3 or 4 days.

Bacillus pyocyaneus.-In the unwashed smoke, both trials, the growth of the organism became visible in one day; but the colony had not entirely reached the top of the slant at the end of the exposure.

Bacillus Kieliensis.-In the first trial the colony of $B$. Kieliensis had just become visible in 6 days. In the second trial it had become visible in 2 days in both raw and washed smoke. By the end of the 7-day period, however, it had developed upon little more than half the length of the slant in raw smoke but over the entire length in washed smoke.

Bacillus rubidus.-In these tests the culture of $B$. rubidus was made on potato, and there was no test in washed smoke. In the tests with raw smoke the cultures required 2 days and 4 days respectively to become visible, while the check in air was visible the day after inoculation in both cases.

Sarcina lutea.-The development of $S$. lutea was hindered by the smoke, more so by that which was untreated than by that which was bubbled through water; but in all cases the colony occupied all of the inoculated area and had produced an abundance of material by the close of the 7-day exposure.

Oidium lactis.-The development of $O$. lactis began promptly in 
smoke at the bottom of the slant and progressed gradually upward. The colony in the washed smoke covered the surface of the agar in considerably less time than that required by the one in raw smoke.

Cryptococcus Ludwigi.-In neither trial did the colony of this yeast in the raw smoke reach the top of the agar slant by the end of the exposure, although the colony in the treated smoke did reach that degree of development. As with most of the other organisms, the development proceeded from the bottom upwards.

Penicillium stoloniferum.-The development of this green mould was retarded in both the treated and untreated smoke. Conidia were produced normally. By the end of the 7 -day period the colony had reached the top of the slant in washed smoke while in the unwashed smoke only the lower half was covered.

The results with the following eight organisms are based on two trials with washed smoke and the same number with unwashed smoke.

Bacterium stewarti. - With B. stewarti the washed smoke, as usual, was less toxic than the unwashed. In the test with untreated smoke the area in which the colony had developed to visibility was still limited to a rather small area at the base of the slant at the end of the 6-day exposure.

Bacillus carotovorus.-The colony of $B$. carotovorus in raw smoke had developed on $1 / 2$ to $3 / 4$ of the agar slant by the end of a week. In washed smoke, however, it had extended the entire length of the slant in 4 and 6 days respectively.

Bacillus melonis.-The colony of $B$. melonis was visible within a day after inoculation in washed smoke, but it required 2 days and 4 days respectively to become visible in the other. In the latter condition, also, the colony had not reached the top of the slant at the end of 6 days in either trial.

Bacillus campestris.-In the first test with raw smoke it took 2 days for the colony of $B$. campestris to become visible and it had progressed upward only about $\mathbf{I ~} \mathrm{cm}$. at the end of 6 days. In the second test for some unknown reason the culture failed to grow at all. In the treated smoke the colony was visible in one day and it had reached the top of the slant in 6 days.

Bacterium tumefaciens.-The colony of B. tumefaciens in untreated smoke did not become visible before 2 days in the more vigorous culture of the two, and in both cases was still confined pretty closely to the base of the slant at the close of the 6-day period. The cultures in the washed smoke grew more vigorously. 
Bacillus solanisaprus.-The presence of smoke, either washed or unwashed, proved to be a hindrance to the growth of this organism, with the washed smoke, as usual, exhibiting the less toxicity.

Pseudomonas radicicola.-There was little difference between the behavior of Ps. radicicola and of the other bacteria in smoke. In the first trial the colony was still confined to the lower half of the slant in the raw smoke at the end of the exposure, while in the second no growth had taken place. In the treated smoke the growth was more vigorous and the colony extended the entire length of the slant.

Bacillus mycoides.-In the case of $B$. mycoides there was in one case no development in raw smoke and in the other the colony was pretty closely confined to the base of the slant. In washed smoke the colonies had spread nearly or quite over the surface of the agar by the time the experiment ended.

It should perhaps be remarked here in connection with the cultures mentioned above that whether specific mention has been made of the check cultures in air or not, it is to be understood that they were made, that they grew promptly (visible within a day), and that they grew over the entire length of the slant.

It thus appears that tobacco smoke is more or less toxic to the organisms used, although it does not seem to exert such extreme toxicity to them as it does to some phanerogams. In view of the very complicated and variable mixture of compounds which constitute smoke, it is hardly worth while to venture an opinion as to which substance or group of substances exerts the toxic influence. It may not be beside the mark, however, to call attention to the fact that the washed smoke was uniformly less toxic in the tests than was the unwashed smoke, and to suggest that something capable either of being condensed or of being dissolved in water has some part in inducing the reactions.

\section{METHYL-IODIDE VAPOR}

The use of methyl-iodide vapor as a test gas for organisms was undertaken as a test of the reliability of some results obtained from methane prepared from methyl iodide by means of the copper-zinc couple; as it was feared that the gas so produced contained some undecomposed methyl-iodide vapor. In the experiments with methyl iodide the chemical was introduced into the culture chamber by dropping the liquid on a bit of absorbent cotton supported by a glass rod 
passing through a rubber stopper. The stopper was immediately put in place in the tubulature of the bell jar which served as the chamber. The liquid then evaporated and diffused to all parts of the chamber, as was amply evidenced by the effects on the cultures. The volume of the jar was approximately 3.8 liters.

In the first trial no measure was secured of the amount of methyl iodide used; but it was considerably more than in the second, where the amount was limited to 5 drops. The results with the different species used were so nearly alike that they will not be discussed separately. The species tested were Bacillus subtilis, $B$. pyocyaneus, $B$. Kieliensis, B. rubidus, Sarcina lutea, Oidium lactis, Cryptococcus Ludwigi, and Penicillium stoloniferum.

Without exception the culture was killed in the test with the larger amount of methyl iodide, $i$. e., there was no development during a 7-day exposure nor within a period of 24 days after. With the smaller amount of the chemical the development was nearly normal in all cases except that there was a slight slowing down of the growth, capable of detection, however, only for periods of $\mathrm{I}$ to 4 days. In addition, the pink yeast was slightly pale in color and B. rubidus (on potato) was clear yellow instead of orange yellow.

In the third test six drops of the liquid were used and in the fourth something more than ten. The organisms used in these two tests were Bacterium stewarti, $B$. tumefaciens, Bacillus carotovorus, $B$. melonis, B. campestris, B. solanisaprus, B. mycoides, and Pseudomonas radicicola.

The development was uniformly greatly inhibited at first but soon began to proceed rapidly so that in the first experiment the treated cultures overtook the checks in about 4 or 5 days on the average. In the second trial, in which the amount of the chemical was doubled or more than doubled, the inhibiting effect was more permanent. Thus Bacillus melonis, $B$. solanisaprus, and Bacterium tumefaciens were the only ones to recover and develop as fully as in the air by the close of a 6-day exposure. Bacillus mycoides would probably have shown an equal ability had inoculation been by means of a streak, as the development near the point of inoculation (the center of the slant only) did show such an ability. The organism, however, showed a reduction in the power to invade the surface of the substratum in the vapor.

The general effect of methyl-iodide vapor on the organisms tested therefore, as shown by the data presented above, is to induce an initial 
great retardation of development followed later by a very vigorous growth unless the amount of the vapor be sufficient to sterilize the inoculated medium, in which case, of course, no development at all follows.

UNIVERSITY OF Michigan, AnN Arbor, Michigan

\section{LITERATURE CITED}

I. Crocker, Wm., and Knight, Lee I. Toxicity of Smoke. Bot. Gaz. 55: 337-37 I. I9I3.

2. Kissling, Rich. Der Gehalt des Cigarrenrauches an Nikotin unter gleichzeitiger Berücksichtigung der giftig wirkenden Verbrennungsprodukte des Tabakes. Dingler's Polytech. Journ. 244: 64-7I, 234-246. I 882.

3. Ludwig, C. A. The Influence of Illuminating Gas and its Constituents on Certain Bacteria and Fungi. Amer. Journ. Bot. 5: 55-60. 1918.

4. Molisch, H. Über den Einfluss des Tabakrauches auf die Pflanzen. Teil I. Sitzungsber. Kais. Akad. Wiss. (Wien) Math.-Nat. Kl. I20: 3-30. I9I I.

5. Tassinari, Vincenzo. Experimentaluntersuchungen über die Wirkung des Tabakrauches auf die Mikroorganismen im allgemeinen und im besonderen auf die Krankheitserzeugenden. Vorl. Mitt. Zentralbl. Bakt. 4: 449-453. I 888 .

6. Thoms, - Constituents of Tobacco Smoke. Süddeutsch. Ap. Zt. 1899: 650. (Abstract in Amer. Journ. Pharm. 72: 227-228. 1900.)

7. Vohl, Herm., and Eulenberg, Herm. Ueber die physiologische Einwirkung des Tabaks als narkotisches Genussmittel, mit besonderer Berücksichtigung der Bestandtheile des Tabakrauches. Archiv. Pharmacie 147: I30-I67. I871. (Abs. in Pharm. Journ. Trans. III. 2: 567-568. I872.) 